on research. Dr Cairns, who before his appointment to Cold Spring Harbor had made some elegant autoradiographical studies of DNA duplication, found on his arrival in Cold Spring Harbor an institution entirely without money, some $\$ 80,000$ in debt and with physical plant requiring at least $\$ 1,000,000$ for restoration to a first-class condition. Over the past five years, Cairns has worked heroically; now much of the laboratory has a strikingly pleasant appearance, and the cash reserves are up to $\$ 125,000$. But after five years of this, Cairns naturally wishes to return to his scientific career.

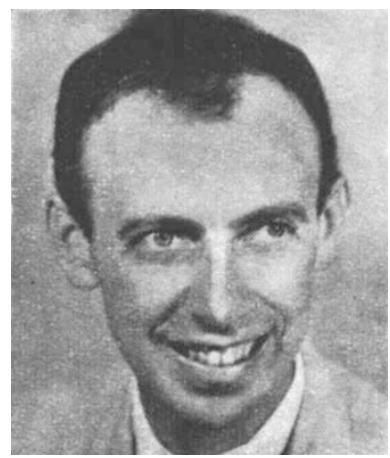

Dr J. D. Watson

The appointment of Dr Watson, already closely connected with the laboratory as a member of the Board of Trustees, and a frequent summer visitor since 1948, should allow a smooth administrative transition. He and Dr Cairns have worked closely together over the past few years, and one of Dr Watson's first aims as director will be to find an endowment for the secure backing of Dr Cairns's position as a staff member. Other immediate objectives will be to find capital funds for a new library to house Cold Spring Harbor's extensive collection of genetic literature, additional summer housing for an enlarged summer course programme and a new laboratory building for expansion of research into the area of molecular biology of higher cells, in particular the multiplication of viruses capable of causing tumours.

\section{Another Hovercraft}

Hovermarine, a small firm based in Southampton, has now produced its first hovereraft, the HM 2 , on licence from Hovercraft Development, Ltd., which handles the patents for the National Research Development Corporation. The design is particularly interest. ing; the hovercraft has submerged sidewalls, so that in motion it looks much like a conventional boat (see picture).

The makers suggest that this sort of craft will be best suited to use in estuaries or rivers, where very large seas are not often experienced. At a speed of $28 \mathrm{knots}$, the craft will comfortably accommodate seas of up to $3 \mathrm{ft}$. in height; in more severe conditions, the company says, the maximum speed attainable will depend on the state of the sea and the amount of discomfort which the passengers are prepared to accept. When hovering, as in the picture, the sidewalls of the craft act as twin keels, giving the craft good directional stability. Shrewdly, Hovermarine says that this will make it possible for operators to pay realistic wage rates to the helmsmen, instead of having to employ skilled pilots. The craft will carry sixty passengers, or sixty-five at full stretch, and costs about $£ 70,000$.

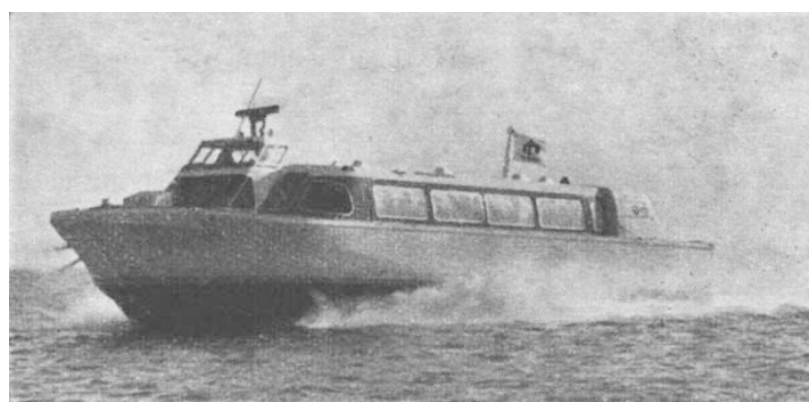

The Hovermarine HM 2 on trials.

In contrast with other hovercraft designs, the Hovermarine HM 2 should be reasonably quiet in operation. It is driven by twin submerged marine screws and not by aircraft-type propellers. Motive power is supplied by two Cummins lightweight diesel engines, and the hover power is supplied by another Cummins engine. The hull is made of glass fibre-reinforced plastics, and the craft can be used from conventional jetties and quays. Hovermarine's own calculations, unsupported as yet by any statistics from operators, show that, at a load factor of 50 per cent and an average speed of 30 knots, operators could make a profit if fares were charged at the rate of $6 d$. a mile. Fares of $9 d$. a mile would produce an annual profit of $£ 25,000$ on the same assumptions, if the craft were depreciated to 10 per cent residual value in 10 years.

\section{Research on Foreign Languages}

IN spite of two British applications to join the European Economic Community, British people remain conspicuously slow at learning foreign languages. There are, however, some signs of impending change, according to the first report of the Committee on Research and Development in Foreign Languages (HMSO, 5s.), which was set up in 1964 under the sponsorship of the Nuffield Foundation, the University Grants Committee, the British Council and what is now the Confederation of British Industry to co-ordinate research and development and to spend a little money-mostly other people's. The chairman is Dr L. Farrer-Brown, a former director of the Nuffield Foundation.

The committee's first experiment was with the teaching of French in primary schools. It has been helped particularly by a pilot scheme begun by the Nuffield Foundation in 1963 which is intended to discover whether a modern language can become a normal part of the primary school curriculum. The report says quite frankly that there are many questions yet to be answered-what is the best starting age ? How much time should be devoted to foreign languages at these tender ages? Are specialists necessary or can ordinary class teachers manage? What is the effect of teaching French on the general performance of the pupils in primary schools? The answers to some of these questions may emerge when the National 